\title{
Effect of amygdalin on the treatment and recurrence of endometriosis in an experimental rat study
}

\author{
HATICE YILMAZ DOGRU 1 \\ CIGDEM KUNT ISGUDER ${ }^{1}$ \\ AKGUL ARICI ${ }^{2}$ \\ ASKER ZEKI OZSOY 1 \\ ILHAN BAHRI DELIBAS ${ }^{1}$ \\ BULENT CAKMAK ${ }^{1}$ \\ ${ }^{1}$ Department of Obstetrics and Gynecology, \\ School of Medicine, Gaziosmanpasa University, \\ Ali Sevki Erek Yerleskesi 60100, Tokat, Turkey \\ ${ }^{2}$ Department of Pathology, School of Medicine, \\ Gaziosmanpasa University, Tokat, Turkey \\ Correspondence: \\ Hatice Y.Imaz Dogru \\ E-mail: hatice_yilmaz47@hotmail.com
}

Keywords: Amygdalin, leuprolide, endometriosis recurrence.
Received November 29, 2016.

Revised July 05, 2017.

Accepted July 09, 2017.

\section{Abstract}

Background: Endometriosis is an aggressive disorder and associated with infertility, pelvic pain and intra-abdominal adhesions in women of reproductive age. Women with endometriosis has the potential risk of recurrence ranging from $21.5 \%$ in two years to $50 \%$ in five years after recovery period. Therefore, there is a certain requirement for new drugs as an alternative therapy to the current ones.

Aim: The aim of the present study is to compare the effects of amygdalin and leuprolide acetate on endometriosis development and recurrence in rats.

Study Design: Animal experiment

Methods: A total of 30 adult female rats were enrolled. Induction of endometriosis was performed by implanting endometriotic focci on the peritoneal side of the abdominal wall. Before amygdalin or leuprolide acetate treatment one of the implant was removed for histopathological analysis, and rats were randomly divided into three groups. Saline (Group 1), amygdalin (Group 2), and leuprolide acetate (Group 3) were administered for three weeks. After treatment, one of the remaining three implants was excised for histopathological evaluation, and all treatments were terminated. Estradiol was given after the estradiol induction for the recurrence of endometriosis. Rest of the implanted tissues were removed, then all rats were euthanised. The implant volumes, histopathological injury and fibrosis levels were observed.

Results: The endometriotic foci volumes in Group 2 and Group 3 were significantly lower than in Group 1 ( $p=0.001, p=0.002$, respectively). The histopathological injury scores and fibrosis levels were not significantly different among the groups ( $p>0.05)$.

Conclusion: The present study showed that amygdalin has an evident effect in the treatment of endometriosis.

\section{INTRODUCTION}

$\mathrm{C}$ ndometriosis is one of the most frequently gynecological disease of Ethe reproductive tract. It is an estrogen-dependent disorder characterized by the implantation and survival of endometrial tissue formed by endometrial stromal and epithelial cells at ectopic sites, frequently in the peritoneal cavity (1). Additionally, it is an aggressive disorder associated with infertility, pelvic pain and intra-abdominal adhesions in women of reproductive age (2). In contrast to the amount of comprehensive studies, the pathogenic mechanism underlying the development of this condition remains unknown $(3,4)$. 
Management of endometriosis consists of surgical or medical therapy. The primary goals of these interventions are the excision of ectopic endometrial tissues, restoration of normal anatomical structures, restriction of the disease progression, and relief of the symptoms $(5,6)$. Medical treatments including oral contraceptives, progestins, androgens, aromatase inhibitors, gonadotropin releasing hormone ( $\mathrm{GnRH})$ agonists, anti-tumor necrosis factor (TNF), and selective estrogen receptor modulators are widely used; however, no significant differences have been found from one to another (7). Women with endometriosis has the potential risk of recurrence ranging from $21.5 \%$ in two years to $50 \%$ in five years after recovery period (8). Therefore, there is a certain requirement for new drugs as an alternative therapy to the current ones.

Leuprolide acetate is a synthetic form of $\mathrm{GnRH}$ receptor agonists and is clinically used in the treatment of endometriosis. It suppresses the production of luteinizing hormone and follicle-stimulating hormone that subsequently lowers gonadal sex steroid production (9). Furthermore, Amygdalin [D-mandelonitrile- $\beta$-D-gentiobioside; vitamin $\mathrm{B} 17\left(\mathrm{C}_{20} \mathrm{H}_{27} \mathrm{NO}_{11}\right)$, also called Laetrile] is a cyanogenic glycoside, extracted from Semen Persicae, and derived from the aromatic amino acid phenylalanine. It was purified in 1830 from the kernels of the bitter almond (Prunus amygdalus) by the French chemists named Robiquet and Boutron-Charlard, and is intensely contained in the seeds of apricots, peaches, and plums. Besides its anti-cancer activity, it has also been administered as an alternative treatment for asthma, bronchitis, emphysema, leprosy, diabetes, and preventing and treating of migraine, hypertension. It has been thought that amygdalin is also an anti-inflammatory agent (10). A recent study by Jiagang et al. showed the influence of amygdalin on the regulation of immune system cells during the development of atherosclerosis (11). It has been proposed that amygdalin could affect the local activity of immune cells which are crucial pathogenic factors in the development and progression of endometriosis (12).

We hypothesized that amygdalin can suppress the endometriotic implants because of its anti-inflammatory effect. A systematic search of the literature revealed that there has been no study conducted to show the effects of amygdalin on endometriosis. In this context, the aim of this study was to evaluate the effects of amygdalin and leuprolide acetate on the treatment and recurrence of endometriosis in a rat model.

\section{MATERIALS AND METHODS}

\section{Chemicals}

Amygdalin and chloral hydrate were purchased from Sigma-Aldrich Chemie GmbH, Taufkirchen, Germany.
Estradiol depot was obtained from Jenapharm, Jena, Germany. Cefazolin sodium was purchased from Eczacıbaşı Pharmaceutical, Istanbul, Turkey. Ketamine and xylazine were obtained from Alfasan International B.V. Haematoxylin Harris and Eosin Y 1\% Alcoholic were purchased from Atom Scientific Ltd (Manchester, UK). Masson's trichrome was obtained from GBL, Istanbul, Turkey. Leuprolide acetate was purchased from Abbott Laboratories, Abbott Park, IL, USA.

\section{Animals}

This prospective, randomized, and controlled experimental study was initiated after approval from Animal Experimentations Local Ethics Board (2014-HADYEK-09). A total of 30 adult female Wistar-Albino rats (90 days-old, nulligravid, 250-300 grams) were obtained from Experimental Medicine Research Unit. Animals were kept in a room maintained at $20-24^{\circ} \mathrm{C}$ with a 12-h light-dark cycle (lights on at 06:00 to 18:00) and a constant humidity of $40-50 \%$. All rats were housed in polycarbonate cages and tap water ad libitum. Before the endometriosis procedures, the estrus cycle of all animals were hormonally synchronized to avoid the possible effects of steroid release, cell adhesion and growth. The estrus cycle was described in the following order: proestrus period (several number of epithelial cells with centric nucleolus), estrus period (cornified epithelial cells with no nuclei), metestrus period (leukocytes, mucus, and a small number of cornified cells), and diestrus period (multiple epithelial cells, mucus, and leukocytes) (13). Rats were followed up until successfully complete at least two 4-day estrus cycles by analyzing vaginal smears periodically.

\section{Endometriosis procedure}

\section{Induction of endometriosis}

All rats were anesthetized using chloral hydrate 300 $\mathrm{mg} / \mathrm{kg}$ intraperitoneally. Endometriosis was induced surgically using the method defined by Lebovic and Uygur et al $(14,15)$. A $3 \mathrm{~cm}$ midline vertical incision was performed to enter the abdominal cavity. The right uterine horn was moved away from the cervix up to a location approximately $1 \mathrm{~cm}$ far from the ovary. The uterine horn was incised longitudinally and divided into four pieces $(0.4 \mathrm{X} 0.4 \mathrm{~cm})$ consisting of both endometrium and myometrium. Pieces were placed in saline solution at $37^{\circ} \mathrm{C}$ and then attached, via the surgical auto-transplantation technique, to the peritoneum with their myometrial side (endometrial side faced to the peritoneal cavity) by using 5-0 Vicryl (polyglactin 910, Ethicon, Somerville, NJ, USA) on the right and left wall of the ventral abdominal side next to an artery. Midline abdominal incision was repaired in a continuous interlocking manner using 3-0 Vicryl (polyglactin 910, Ethicon, Somerville, NJ, USA). Cefazolin sodium 50 

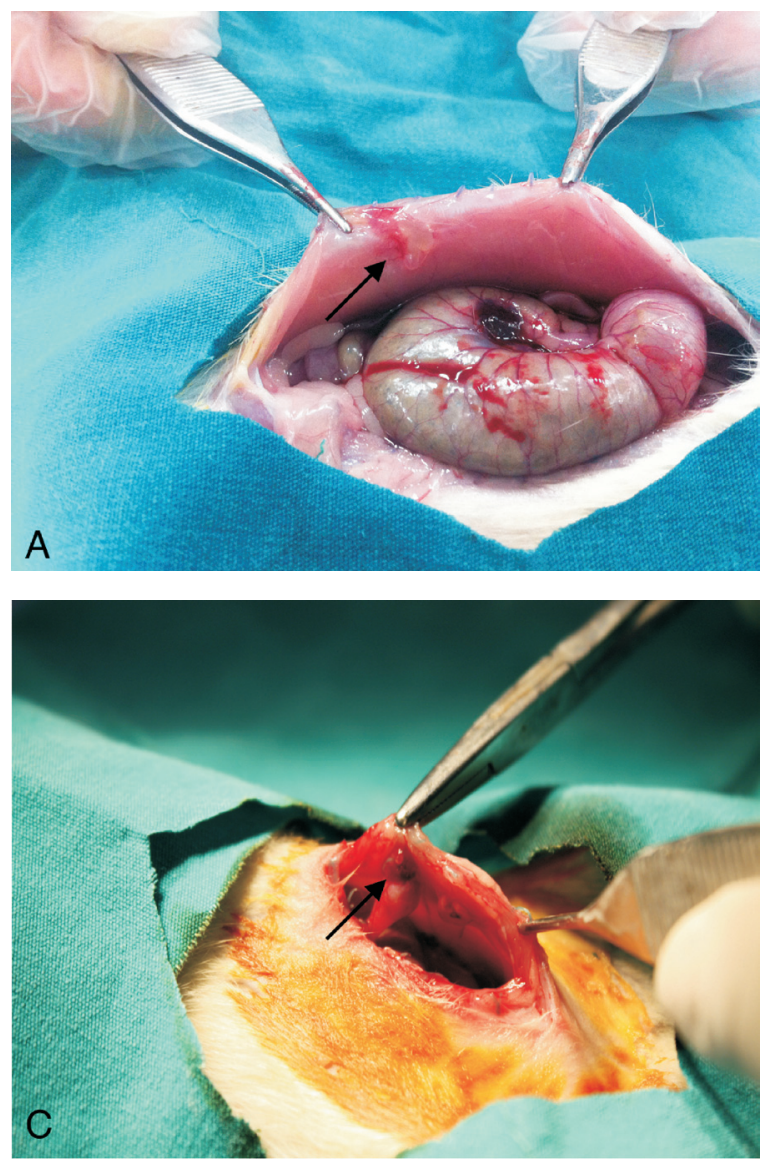
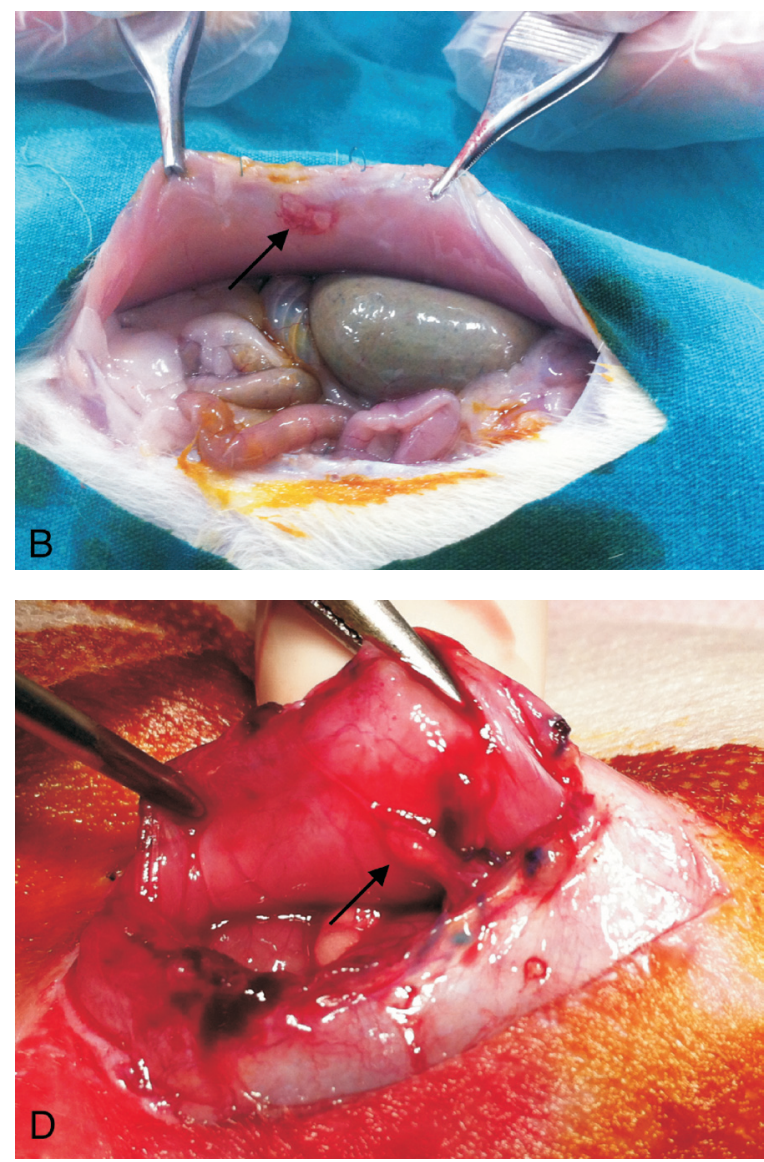

Figure 1. Macroscopic images of endometriotic implant: $\mathbf{A}$ - before amydalin or LA treatment; $\mathbf{B}$ - after treatment; $\mathbf{C}$ - before amydalin or LA treatment; $\mathbf{D}$ - after treatment.

$\mathrm{mg} / \mathrm{kg}$ for three days and estradiol depot $50 \mathrm{mg} / \mathrm{kg} \mathrm{IM}$ twice a week were administered to all rats in the postoperative period to reduce the duration of endometriosis induction and increase the efficiency (16).

\section{Before amygdalin or LA treatment}

This procedure was initiated 21 days after the induction of endometriosis. The implanted tissues were documented, and the height, length and width of the tissues were measured by a micrometer (Figure 1). The implant volume was computed using the formula of ellipsoid volume $(\pi / 6 \times$ length $\times$ width $\times$ height $)$. One of the four implants was excised for histopathological analysis. After no significant difference was found between removed tissue volumes following excision the rats were randomly divided into three groups as follows: Group 1 received 1 $\mathrm{ml}$ of saline $0.9 \%$ (Adeka, Istanbul, Turkey) intraperitoneally once a week, Group 2 received amygdalin $5 \mathrm{mg} / \mathrm{kg}$ intraperitoneally once a week, and Group 3 received leuprolide acetate $0.0375 \mathrm{mg} / \mathrm{kg}$ subcutaneously once a week. The doses of amygdalin and leuprolide acetate were used as indicated in the study conducted by Guo et al. and Dolapciogu et al., respectively $(17,18)$.

\section{After treatment}

This procedure was performed 21 days after the previous one. The height, length and width of the tissues were measured by a micrometer, and one of the rest three implanted tissues was removed for histopathological evaluation. Thereafter, all medications were terminated and remaining estradiol injections for recurrence of endometriosis (estradiol depot $50 \mathrm{mg} / \mathrm{kg}$ IM twice a week) were given until the last operation.

\section{After the estradiol induction for the recurrence of endometriosis}

After 21 days of estradiol treatment, all rats were evaluated for visible signs of recurrent growth under chloral hydrate anesthesia, and remaining implanted tissues on the abdominal wall were removed. All rats were euthanized by administering ketamine $50 \mathrm{mg} / \mathrm{kg}$ and xylazine $10 \mathrm{mg} / \mathrm{kg}$ intraperitoneally.

\section{Histopathological evaluation}

The tissue samples harvested from all animals were fixed in $10 \%$ neutral buffered formalin solution for 24 hours, quickly upon collection. Samples were dehydrated 

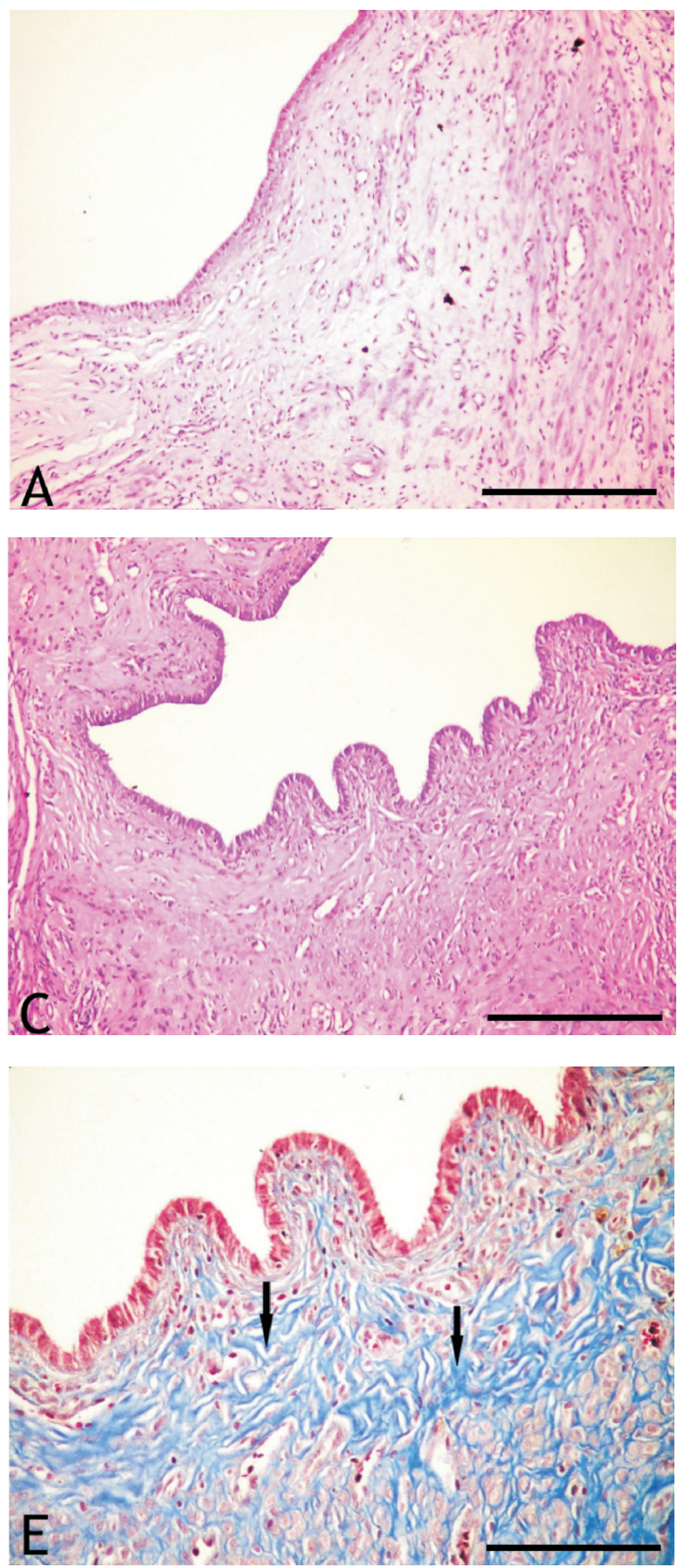
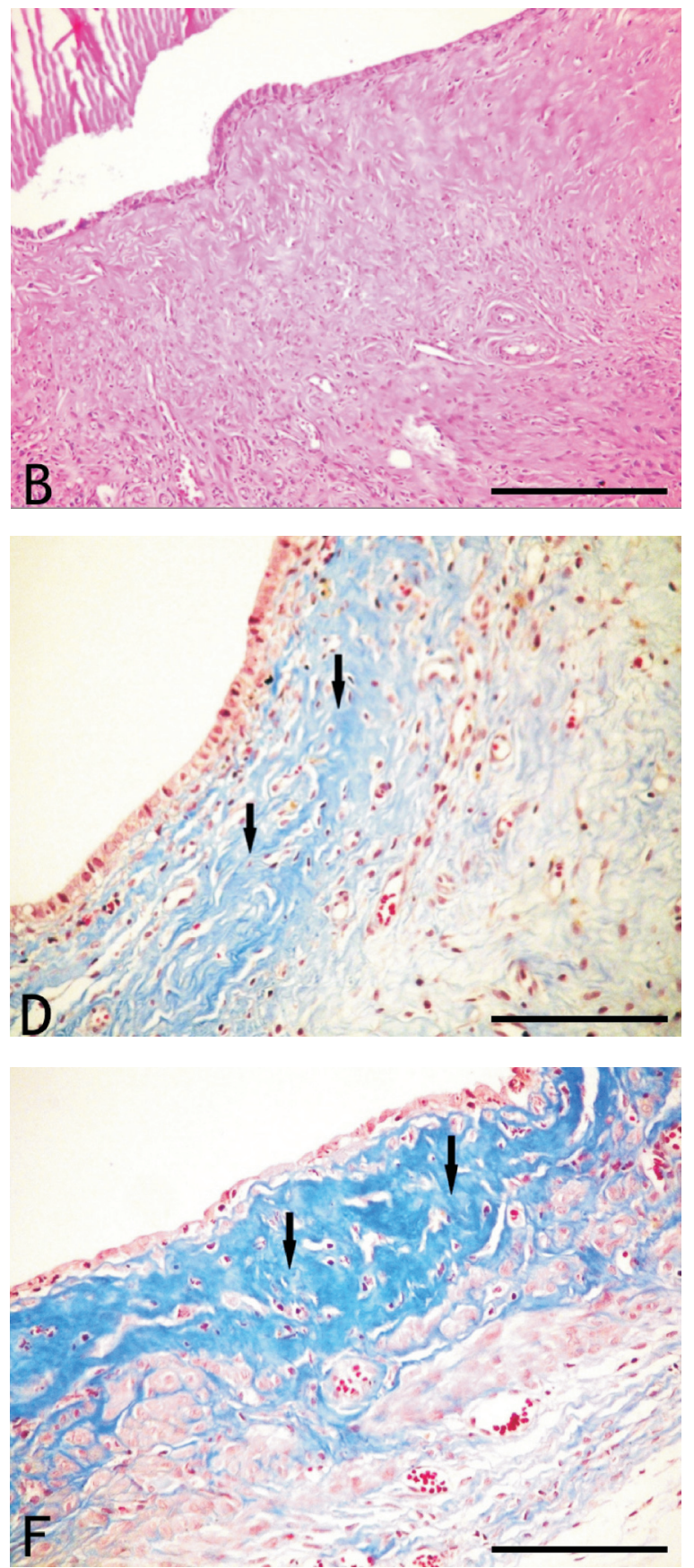

Figure 2. Histopathological evaluation of endometriotic implant. A - Well-preserved superficial epithelium and elevated stromal vessel density (Group 1); B - Evident stromal fibrosis, mild leukocyte infiltration and moderate preserved epithelium (Group 2); $\mathbf{C}-$ Congestion in sub-epithelial stroma and mild fibrosis (Group 3); D - [+] fibrosis in Group 1; E - [++] fibrosis in Group 3; $\mathbf{F}-[+++]$ fibrosis in sub-epithelial stroma of Group 2.

A-C: H\&E staining, Magnification: $\times 100$, Scale bar: 200 micrometer; D-F: Masson's Trichrome staining, Magnification: $\times 200$, Scale bar: 100 micrometer.

and embedded in paraffin for histopathological evaluation. Five $\mu \mathrm{m}$ thick sections were prepared from paraffinembedded samples and mounted on glass slides. For histopathological assessment under light microscope (Nikon Eclipse E600W, Japan), the mounted sections were stained with hematoxylin and eosin (H\&E) and Masson's trichrome by a pathologist blinded to the study groups. A grading scale for the structure of epithelial cells in the implants described by Keenan et al. was used to determine the histopathological score of the sample tis- 

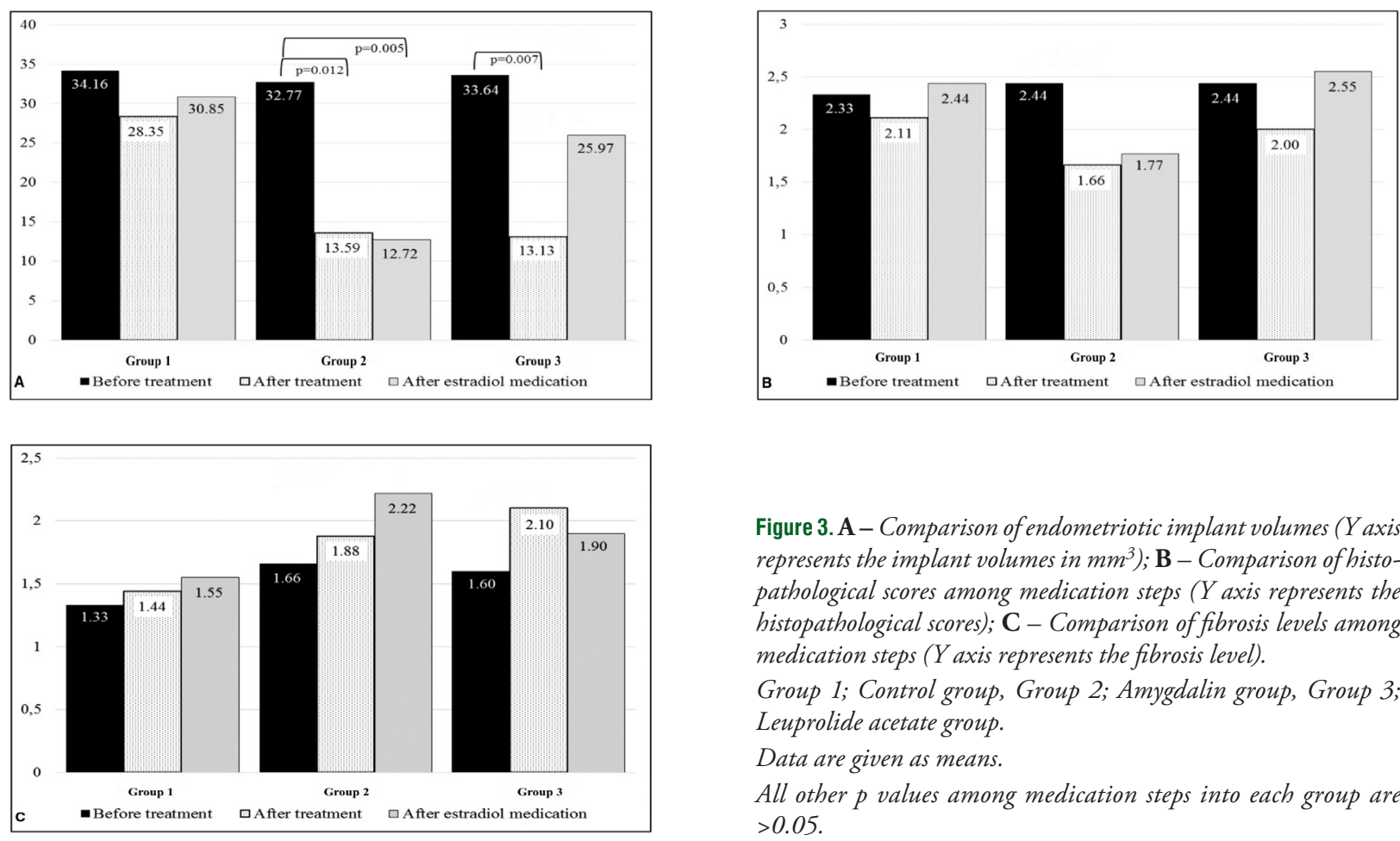

Figure 3. A-Comparison of endometriotic implant volumes ( $Y$ axis represents the implant volumes in $\left.\mathrm{mm}^{3}\right) ; \mathbf{B}$ - Comparison of histopathological scores among medication steps ( $Y$ axis represents the histopathological scores); C - Comparison of fibrosis levels among medication steps ( $Y$ axis represents the fibrosis level).

Group 1; Control group, Group 2; Amygdalin group, Group 3; Leuprolide acetate group.

Data are given as means.

All other $p$ values among medication steps into each group are $>0.05$.

Table 1. Histopathologic comparison of the endometriotic implants among the groups

\begin{tabular}{|c|c|c|c|c|c|c|}
\hline Histopathologic features of implants & $\begin{array}{c}\text { Group } 1 \\
(\mathrm{n}=9)\end{array}$ & $\begin{array}{c}\text { Group } 2 \\
(\mathrm{n}=10)\end{array}$ & $\begin{array}{c}\text { Group } 3 \\
(\mathrm{n}=10)\end{array}$ & $\mathrm{p} 1$ & $\mathrm{p} 2$ & p3 \\
\hline \multicolumn{7}{|l|}{ Endometriotic foci volumes $\left(\mathrm{mm}^{3}\right)$} \\
\hline Before treatment & $34.16 \pm 4.55$ & $32.77 \pm 6.85$ & $33.64 \pm 7.81$ & 0.561 & 0.963 & 0.677 \\
\hline After treatment & $28.35 \pm 7.47$ & $13.59 \pm 7.75$ & $13.13 \pm 6.64$ & 0.002 & 0.001 & 0.813 \\
\hline After estradiol medication & $30.85 \pm 8.15$ & $12.72 \pm 8.56$ & $25.97 \pm 7.65$ & 0.002 & 0.173 & 0.007 \\
\hline \multicolumn{7}{|l|}{ Histopathological scores } \\
\hline Before treatment & $2.33 \pm 0.86$ & $2.44 \pm 0.72$ & $2.44 \pm 1.01$ & 0.964 & 0.783 & 0.734 \\
\hline After treatment & $2.11 \pm 1.05$ & $1.66 \pm 1.05$ & $2.00 \pm 1.00$ & 0.156 & 0.729 & 0.33 \\
\hline After estradiol medication & $2.44 \pm 0.52$ & $1.77 \pm 0.83$ & $2.55 \pm 0.52$ & 0.072 & 0.647 & 0.042 \\
\hline \multicolumn{7}{|l|}{ Fibrosis levels } \\
\hline Before treatment & $1.33 \pm 0.50$ & $1.66 \pm 0.70$ & $1.60 \pm 0.69$ & 0.172 & 0.399 & 0.565 \\
\hline After treatment & $1.44 \pm 0.52$ & $1.88 \pm 0.78$ & $2.10 \pm 0.73$ & 0.121 & 0.05 & 0.776 \\
\hline After estradiol medication & $1.55 \pm 0.72$ & $2.22 \pm 0.83$ & $1.90 \pm 0.73$ & 0.091 & 0.288 & 0.36 \\
\hline
\end{tabular}

* Multiple comparisons were completed using one-way ANOVA test, posthoc analysis were conducted by Tukey's HSD test.

Bonferrroni corrected p value was used for significance as $\mathrm{p}<0.016$. Group 1; Control group, Group 2; Amygdalin group, Group 3; Leuprolide acetate group. Data are given as means \pm standard deviation.

The significance between the groups:

p1; group 1 - group 2, p2; group 1 - group 3, p3; group 2 - group 3

sue. Well-preserved epithelium, Grade 3; leukocyte infiltration and moderately protected epithelium, Grade 2; slightly preserved, very infrequently observed epithelium, Grade 1; disappearance of epithelial line, Grade 0 (16). According to this scoring system, lower scores shows impaired histological structure. Sections stained by Masson's trichrome for observing the fibrosis intensity were assessed by the method described by Erdemir et al (19). The collagen density in the samples obtained from implanted tissues was assessed and graded on scales 
ranging from $1+$, the lowest density collagen, to $4+$, the highest density collagen ratios under light microscopy $(\times 400)$.

\section{Statistical analysis}

All analyses were performed using the Statistical Package for Social Sciences (SPSS Inc., Chicago, IL) version 20.0 program. Multiple comparisons were conducted by one-way ANOVA test and posthoc analysis using Tukey's HSD test. Continuous variables were expressed as means \pm standard deviation. Bonferrroni corrected $\mathrm{p}$ value was used for all analysis as $\mathrm{p}<0.016$.

\section{RESULTS}

Endometriosis was successfully induced in all groups. The mean (initial) weight of the rats after grouping was 272.8 grams and 274.7 grams in Group 2 and 3, and 269.2 grams in Group 1 ( $p>0.05$ ). No complications were observed among rats; however, one rat in Group 1 died during the study period.

The endometriotic implant volumes were presented in Table 1. Microscopic evaluation of the sections among groups was shown in Figure 2 (A, B, C, D, E, F). After amygdalin or leuprolide acetate treatment, the endometriotic implant volumes in Group 1, Group 2 and Group 3 were $28.35 \mathrm{~mm}^{3}, 13.59 \mathrm{~mm}^{3}$ and $13.13 \mathrm{~mm}^{3}$, respectively. The endometriotic implant volumes after amygdalin or leuprolide acetate treatment in Group 2 and Group 3 were significantly lower than in Group 1 ( $\mathrm{p}=0.002$ and $\mathrm{p}=0.001$, respectively). After estradiol medication, the implant volume in Group 2 was significantly lower compared to Group 1 and Group 3 ( $\mathrm{p}=0.002$ and $\mathrm{p}=0.007$, respectively). The implant volumes in Group 2 progressively decreased from the beginning of the amygdalin treatment to the end of the estradiol medication ( $p$ $=0.012, p=0.005$; Figure $3 \mathrm{~A}$ ). The endometriotic implant volumes in Group 3 were significantly lowered after leuprolide treatment compared to the beginning of the treatment $(\mathrm{p}=0.007$; Figure $3 \mathrm{~A})$. The mean histopathological scores were presented in Table 1 . The fibrosis levels were not significantly different among the groups ( $\mathrm{p}>0.05$; Table 1).

\section{DISCUSSION}

The present study revealed that amygdalin apparently lowered the volumes of the endometriotic implant compared to leuprolide acetate after estradiol medication. Additionally, a clinically evident decrease in histopathological score was observed by amygdalin compared to leuprolide acetate treatment after estradiol medication. Several drugs have been used for the endometriosis therapy in the clinical setting (8). However, none could provide a stable long-term benefit and recurrence rates have been found to be high after ceasing of treatment. Simsek et al. investigated atosiban (an oxytocin receptor blocking agent) and found that atosiban treatment decreased the endometriotic implant volumes (13). Recently, Dolapcioglu et al. compared the effects of theranekron, medroxyprogesterone acetate and leuprolide acetate in a rat endometriosis model, and showed that theranekron led to improvement in endometriosis and exhibited a declined ratio of recurrence (17). Nevertheless, current studies also indicated that amygdalin might be helpful for the treatment of fibrosis in the liver and kidney (18). Yang et al. reported that amygdalin can suppress fibroblast proliferation and disrupts the process of renal interstitial fibrosis, and they concluded that the possible mechanism behind this cascade of events could be the increase in the type I collagenase secretion, which restricts fibroblast proliferation, induction of apoptosis, and suppression of type I collagenase by amygdalin (20).

In this context, the present study revealed that amygdalin is superior to leuprolide acetate in reducing the implant volumes and maintaining its consistency by displaying no visible signs of recurrent growth after the treatment ended. It is reported that amygdalin exhibits its effect by excreting cyanide through susceptible cells, resulting in cell death by cyanide toxicity. The toxicity of cyanide might occur in tissue containing glucosidase enzymes, which splits off glucose from amygdalin and prunasin (21). In relation, a clinical trial by Brandelli et al. showed that women with endometriosis have an increased activity of glucosidases in the peritoneal fluid (22). Amygdalin also leads to slightly increased but not significant fibrosis levels compared to initial, and provided this level after the end of amygdalin treatment that considered as diminishing of endometriotic implant with no visible signs of recurrent growth. A possible mechanism making a connection with the previous data is that endometrial tissue in the implants could be deteriorated by the cyanide toxicity of the endometriotic cells not the components of the connective tissue such as fibroblasts due to the enzymatic metabolization of amygdalin by glucosidases. Cyanide induced the production of reactive oxygen species provided the activation of $\mathrm{p} 38$ mitogen-activated protein kinase and nuclear accumulation of hypoxia-inducible factor-1-alpha those lead to apoptosis (23). To the extent of our knowledge, this is the first experimental study conducted to determine the effects of amygdalin on endometriosis treatment and recurrence, and the first time such an observation has been demonstrated in an endometriosis model. Amygdalin is a cyanogenic glycoside, wherein cyanide is the main reason of toxicity. The lethal dose is estimated to be between $50-300 \mathrm{mg}$ for humans while taking orally, or a blood level over $3 \mathrm{microg} / \mathrm{ml}$. However, oral administration is associated with higher incidence of toxicity than intravenous, intraperitoneal, or intramuscular injection because the human intestinal microflora possesses enzymes capable of effecting cyanide release. Recent research suggests an oral dose of $0.6-1.0 \mathrm{gr}$ can 
avoid toxicity in humans (24). In contrast, there is no data available on the dosage of amygdalin in patients with endometriosis.

It is well-demonstrated that three drugs for the treatment of endometriosis including progestins, GnRH agonists and androgenic agents prevent the proliferation of the implants and provide diminished adhesion formation. Vercellini et al. reported that the use of GnRH analogs prevents the risk of recurrence after surgery in patients with moderate or severe endometriosis (25). In contrast, some studies have been unsuccessful to show any evidence about the effects of post-operative medication in reducing endometriosis recurrence (26-39). Recent findings demonstrated that post-surgical hormonal therapy for endometriosis has no improvement on pain relief or pregnancy rates, but a substantial decrease in endometriosis recurrence rate solely (30). However, there has been no satisfactory evidence found to confirm the effects of hormonal suppression therapy and surgical approach on endometriosis. Therefore, the outcomes of the present study may provide additional information about the development and recurrence of this disease.

There are some limitations in the present study. First, this is an experimental study with restricted numbers of rats per group. This was related to our ethical rules regarding keeping to the 'principle of reduction' in animal experiments; however, studies with larger populations would be required to find minimal histopathological differences among groups. Second, a subjective scoring system was performed to assess the histopathological changes of the endometriotic implant. A standardized image-analysis program providing an automated interpretation of histopathological changes would be better to meet with a more accurate result, which currently is not available.

In conclusion, the present study demonstrated that amygdalin can suppress the progression of endometriosis and its recurrence. Amygdalin might be more beneficial both in the treatment and the prevention of visible signs of recurrent lesions than leuprolide acetate.

Ethics Committee Approval: Ethics committee approval was received for this study from the Animal Experimentations Local Ethics Board (2014-HADYEK-09).

\section{Informed Consent: N/A.}

Author contributions: Concept - H.Y.D.., Ç.K.İ; Design - H.Y.D.; Supervision - H.Y.D., B.Ç., A.A.; Resource - H.Y.D., A.A.; Materials - H.Y.D.; Data Collection and/or Processing - H.Y.D., İ.B.D.; Analysis and/or Interpretation - H.Y.D., A.A.; Literature Search - H.Y.D., A.Z.Ö.; Writing - H.Y.D., B.Ç., İ.B.D.; Critical Reviews - H.Y.D., Ç.K.İ., A.A., A.Z.Ö., İ.B.D., B.Ç.

Conflict of Interest: No conflict of interest was declared by the authors.
Financial Disclosure: This study was funded by Gaziosmanpasa University Scientific Research Projects Unit (Grant number: 2014/10).

\section{REFERENCES}

1. YAMANAKA A, KIMURA F, TAKEBAYASHI A, KITA N, TAKAHASHI K, MURAKAMI T 2012 Primate model research for endometriosis. Tohoku Journal of Experimental Medicine 226: 95-99. https://doi.org/10.1620/tjem.226.95

2. FORTIN M, LÉPINE M, PAGÉ M, OSTEEN K, MASSIE B, HUGO P, STEFF AM 2003 An improved mouse model for endometriosis allows noninvasive assessment of lesion implantation and development. Fertility and Sterility 80 Suppl 2: 832-838. https://doi.org/10.1016/S0015-0282(03)00986-5

3. GRÜMMER R 2006 Animal models in endometriosis research. Human Reproduction Update 12: 641-649. https://doi.org/10.1093/humupd/dml026

4. GUO SW 2009 Recurrence of endometriosis and its control. $\mathrm{Hu}$ man Reproduction Update 2009 15: 441-461. https://doi.org/10.1093/humupd/dmp007

5. LU D, SONG H, SHI G 2013 Anti-TNF- $\alpha$ treatment for pelvic pain associated with endometriosis. Cochrane Database Systematic Review 3: CD008088. https://doi.org/10.1002/14651858.CD008088.pub3

6. YAP C, FURNESS S, GARQUHAR C 2004 Pre and post operative medical therapy for endometriosis surgery. Cochrane Database Systematic Review 3: CD003678.

7. RICE VM 2002 Conventional medical therapies for endometriosis. Annals of the New York Academy of Sciences 955: 343-352. https://doi.org/10.1111/j.1749-6632.2002.tb02795.x

8. BROWN J, FARQUHAR C 2014 Endometriosis: an overview of Cochrane Reviews. Cochrane Database Systematic Review 3: CD009590. https://doi.org/10.1002/14651858.CD009590.pub2

9. WILSON AC, MEETHAL SV, BOWEN RL, ATWOOD CS 2007 Leuprolide acetate: a drug of diverse clinical applications. Expert Opinion Investigational Drugs 16: 1851-1863. https://doi.org/10.1517/13543784.16.11.1851

10. HALENAR M, MEDVEDOVA M, MARUNIAKOVA N, KOLESAROVA A 2013 Amygdalin and its effects on animal cells. Journal of Microbiology, Biotechnology and Food Sciences 2 (Special issue): 1414-1423

11. JIAGANG D, LI C, WANG H, HAO E, DU Z, BAO C, LV J, WANG Y 2011 Amygdalin mediates relieved atherosclerosis in apolipoprotein $\mathrm{E}$ deficient mice through the induction of regulatory $\mathrm{T}$ cells. Biochemical and Biophysical Research Communications 411: 523-529. https://doi.org/10.1016/j.bbrc.2011.06.162

12. ABBAS MA, TAHA MO, DISI AM, SHOMAF M 2013 Regression of endometrial implants treated with vitamin D3 in a rat model of endometriosis. European Journal of Pharmacology 715: 72-75. https://doi.org/10.1016/j.ejphar.2013.06.016

13. SIMSEK Y, CELIK O, KARAER A, GUL M, YILMAZ E, KOC O, COLAK C, ZENGIN S, AYDIN NE 2012 Therapeutic efficiency of Atosiban, an oxytocin receptor blocking agent in the treatment of experimental endometriosis. Archives of Gynecology and Obstetrics 286: 777-783.

https://doi.org/10.1007/s00404-012-2390-7

14. LEBOVIC DI, KIR M, CASEY CL 2004 Peroxisome proliferatoractivated receptor-gamma induces regression of endometrial explants in a rat model of endometriosis. Fertility and Sterility 82 (Suppl 3): 1008-1013.

https://doi.org/10.1016/j.fertnstert.2004.02.148

15. UYGUR D, AYTAN H, ZERGEROGLU S, BATIOGLU S 2006 Leflunomide--an immunomodulator--induces regression of endo- 
metrial explants in a rat model of endometriosis. Journal of the Society for Gynecologic Investigation 13: 378-383. https://doi.org/10.1016/j.jsgi.2006.03.006

16. KEENAN JA, WILLIAMS-BOYCE PK, MASSEY PJ, CHEN TT, CAUDLE MR, BUKOVSKY A 1999 Regression of endometrial explants in a rat model of endometriosis treated with the immune modulators loxoribine and levamisole. Fertility and Sterility 72: 135-141. https://doi.org/10.1016/S0015-0282(99)00157-0

17. DOLAPCIOGLU K, DOGRUER G, OZSOY S, ERGUN Y, CIFTCI S, SOYLU KARAPINAR O, ASLAN E 2013 Theranekron for treatment of endometriosis in a rat model compared with medroxyprogesterone acetate and leuprolide acetate. European Journal of Obstetrics \& Gynecology and Reproductive Biology 170: 206-210. https://doi.org/10.1016/j.ejogrb.2013.05.026

18. GUO J, WU W, SHENG M, YANG S, TAN J 2013 Amygdalin inhibits renal fibrosis in chronic kidney disease. Molecular Medicine Reports 7: 1453-1457.

19. ERDEMIR F, FIRAT F, MARKOC F, ATLIGAN D, PARLAKTAS BS, KUYUCU YE, GENCTEN Y 2014 The effect of pentoxifylline on penile cavernosal tissues in ischemic priapism-induced rat model. International Urology and Nephrology 46: 1961-1967.

20. YANG C, LI X2, RONG J 2014 Amygdalin isolated from Semen Persicae (Tao Ren) extracts induces the expression of follistatin in HepG2 and C2C12 cell lines. Chinese Medicine 9: 23. https://doi.org/10.1186/1749-8546-9-23

21. NEWMARKJ, BRADY RO, GRIMLEY PM, GALAE, WALLER SG, THISTLETHWAITE JR 1981 Amygdalin (Laetrile) and prunasin beta-glucosidases: distribution in germ-free rat and in human tumor tissue. Proceedings of the National Academy of Sciences USA 78: 6513-6516. https://doi.org/10.1073/pnas.78.10.6513

22. BRANDELLI A, PASSOS EP 1998 Glycosidases in the peritoneal fluid from infertile women with and without endometriosis. Clinical Biochemistry 31: 181-186. https://doi.org/10.1016/S0009-9120(98)00012-5

23. ZHANG L, LIU H, PRABHAKARAN K, ZHANG X, BOROWITZ JL, ISOM GE 2007 HIF-1alpha Activation by a Redox-Sen- sitive Pathway Mediates Cyanide-induced BNIP3 Upregulation and Mitochondrial Dependent Cell Death. Free Radical Biology and Medicine 1; 43: 117-127.

https://doi.org/10.1016/j.freeradbiomed.2007.04.005

24. MILAZZO S, LEJEUNE S, ERNST E 2007 Laetrile for cancer: a systematic review of the clinical evidence. Support Care Cancer 15: 583-595. https://doi.org/10.1007/s00520-006-0168-9

25. VERCELLINI P, CROSIGNANI PG, FADINI R, RADICI E, BELLONI C, SISMONDI P 1999 A gonadotrophin-releasing hormone agonist compared with expectant management after conservative surgery for symptomatic endometriosis. British Journal of Obstetrics and Gynaecology 106: 672-677. https://doi.org/10.1111/j.1471-0528.1999.tb08366.x

26. BUSACCA M, CHIAFFARINO F, CANDIANI M, VIGNALI M, BERTULESSI C, OGGIONI G, PARAZZINI F 2006 Determinants of long-term clinically detected recurrence rates of deep, ovarian, and pelvic endometriosis. American Journal of Obstetrics \& Gynecology 195: 426-432. https://doi.org/10.1016/j.ajog.2006.01.078

27. KIKUCHI I, TAKEUCHI H, KITADE M, SHIMANUKI H, KUMAKIRI J, KINOSHITA K 2006 Recurrence rate of endometriomas following a laparoscopic cystectomy. Acta Obstetricia et Gynecologica Scandinavica 85: 1120-1124. https://doi.org/10.1080/00016340600627154

28. KOGA K, TAKEMURA Y, OSUGA Y, YOSHINO O, HIROTA Y, HIRATA T, MORIMOTO C, HARADA M, YANO T, TAKETANI Y 2006 Recurrence of ovarian endometrioma after laparoscopic excision. Human Reproduction 21: 21712174. https://doi.org/10.1093/humrep/del125

29. LIU X, YUAN L, SHEN F, ZHU Z, JIANG H, GUO SW 2007 Patterns of and risk factors for recurrence in women with ovarian endometriomas. Obstetrics \& Gynecology 109: 1411-1420. https://doi.org/10.1097/01.AOG.0000265215.87717.8b

30. YAP C, FURNESS S, FARQUHAR C 2004 Pre and post operative medical therapy for endometriosis surgery. Cochrane Database Systematic Review: CD003678. 